máu tăng qua các giai đoạn bệnh thận mạn và có mối tương quan có ý nghĩa thống kê với chức năng thâan vì vậy trong thực hành lâm sàng theo dõi và điều trị bệnh thận mạn cần kiểm soát chă̆t chẽ nồng độ acid uric máu hạn chế sự tiến triển của bệnh thận mạn. Cần có những nghiên cứu sâu hởn đánh giá hiệu quả việc lựa chọn thuốc kiểm soát acid uric cho bệnh nhân bị bệnh thận mạn.

\section{TÀl LIỆU THAM KHẢO}

1. Annual Data Report (2014), "CKD in the United States: An Overview of the USRDS Annual Data Report, Volume 1", 1-9.

2. Nguyển Văn Tuấn (2015), "Nghiên cứu nồng độ TGF-beta1 Và hs-CRP huyêt thanh ở bênh nhân bị bênh thân mạn", Luận án Tiến sỹ Y học. Đại học Y Dược Huế.

3. KDIGO (2012), "KDIGO 2012 Clinical practice guideline for the evaluation and management of chronic kidney disease", Kidney International supplements. 3((1)), 5-14.

4. Levey A. S (2009), "A new equation to estimate glomerular filtration rate", Ann Intern Med. 150(9), 604-12.

5. Zhu Y, Pandya B. J Choi H. K (2012), "Comorbidities of gout and hyperuricemia in the US general population: NHANES 2007-2008", Am J Me्d. 125(7), 679-687.

6. Đố Gia Tuyển, Đăng Thi Viêt Hà Nguyễn Thị An Thủy (2016), "Tình trang rối loan Acid uric máu ở bệnh nhân suy thận mạn chưa điều tri thay thế", Tap chí nghiên cứu y hoc. 101(3), 143 - 150.

7. Liu X (2018), "Effects of uric acid-lowering therapy on the progression of chronic kidney disease: a systematic review and meta-analysis", Renal Failure. 40(1), 289-297.

8. Trinh Kiến Trung (2015), "Nghiên cứu nồng đố acid uric máu, bệnh gout và hội chứng chuyển hóa ở người từ 40 tuổi trở lên tại thành phố Cần Thơ", Luận án Tiến sĩ Y học.

\title{
NGHIÊN CỨU MỐI LIÊN QUAN GIỮA CHİ SỐ ABI, TỐC Độ LAN TRUYỀN SÓNG MACH VỚI MỨC Độ TỔN THƯƠNG ĐộNG MACH VÀNH THEO THANG ĐIỂM SYNTAX II Ở BÊNNH NHÂN NHỒI MÁU CO' TIM CẤP
}

\author{
Nguyễn Đình Linh ${ }^{1}$, Hồ Thị Kim Ngân ${ }^{1}$, Trần Đức Hùng ${ }^{2}$
}

\section{TÓM TẮT}

Mục tiêu: Tìm hiểu mối liên quan giữa chỉ số huyết áp tâm thu cổ chân-cánh tay (Ankle Brachial Index - $A B I$ ), tốc độ lan truyền sóng mạch (pulse wave velocity - PWV) với mức đô tổn thương động mạch vành (ĐMV) ở bệnh nhân (BN) nhồi máu cơ tim (NMCT) cấp. Đối tướng và phương pháp nghiên cứu: Nghiên cứu mô tả cắt ngang trên 2 nhóm: nhóm bênh gồm 60 người bi NMCT cấp và nhóm chứng gồm 33 người có cùng độ tuổi và các yếu tố nguy cơ và chụp ĐMV không tổn thương. Cả 2 nhóm đêu được đo $A B I, P W V$, chụp ĐMV, nhóm bệnh được đánh giá mức độ tổn thương theo thang điểm SYNTAXX II. Kết quả: Tuổi trung bình của nhóm bệnh và nhóm chứng tương ứng là $67,05 \pm 12,04$ và $67,67 \pm 6,80$ năm. ABI của nhóm bệnh $(1,04 \pm 0,10)$ thấp hơn nhóm chứng $(1,12 \pm 0,13), p<0,01$. PWV của nhóm bệnh $(15,90$ $\pm 1,49 \mathrm{~m} / \mathrm{s})$ cao hơn nhóm chứng $(13,32 \pm 1,98 \mathrm{~m} / \mathrm{s})$, $p<0,01$. PWV ở nhóm tổn thương 1 nhánh và $\geq 2$ nhánh tương ứng là $15,25 \pm 1,09 \mathrm{~m} / \mathrm{s}$ và $16,22 \pm$ $1,57 \mathrm{~m} / \mathrm{s}$. Có sự tương quan chặt chẽ giữa PWV với điểm SYNTAX $(r=0,477 ; p<0,01)$. Kết luân: ở nhóm NMCT cấp PWV cao hơn và $A B I$ thấp hơn nhóm chứng có ý nghĩa. PWV tương quan chă̆t chẽ với mức độ tổn thương ĐMV theo thang điểm SYNTAX II.

${ }^{1}$ Học viện Quân y

²Bênh viên Quân y 103

Chịu trách nhiệm chính: Trân Đức Hùng

Email: tranduchung2104@gmail.com

Ngày nhân bài: 15.9.2021

Ngày phản biên khoa hoc: 12.11.2021

Ngày duyệt bài: 22.11.2021
Tư khóa: Nhồi máu cơ tim cấp, vận tốc lan truyền sóng mạch,SYNTAX II.

\section{SUMMARY \\ RELATIONSHIP BETWEEN ANKLE-BRACHIAL INDEX, PULSE WAVE VELOCITY WITH CORONARY ARTERY LESION SEVERITY ASSESSED BY SYNTAX II SCORE IN PATIENTS WITH ACUTE MYOCARDIAL INFARCTION}

Objectives: research about relationship between Ankle-Brachial Index, Brachial-Ankle Pulse Wave Velocity and coronary artery disease severrity assessed in patients with acute myocardial infarction. Subjects and methods: This cross-sectional registry study was done at 103 military hospital Cardiovascular Center in patients with acute myocardial infarction and controls from November 2020 to April 2021. Results: 93 subjects including 60 patients with AMI (mean age $67,05 \pm 12,04$ ) and 33 without CAD (mean age $67,67 \pm 6,80)$ were enrolled in the study. Patients with AMI had significantly higher PWV and lower ABI as compared to controls $(15,90 \pm 1,49$ vs $13,32 \pm 1,98$; $\mathrm{p}<0,01),(1,04 \pm 0,10$ vs $1,12 \pm 0,13 ; p<0,01)$. The $A B I$ $\geq 0.9$ did not show any correlation with the number of branches and the degree of coronary artery injury. PWV was associated with number of diseased coronary artery $(15,25 \pm 1,09$ so với $16,22 \pm 1,57)$. There were strong correlations between PWV and SYNTAX score $(r=0,477$; $\mathrm{p}<0,01)$. Conclusion: This study provided the frank direct evidence in a cross-sectional investigation that PWV is associated with the extent of coronary artery disease. Keywords: Acute Myocardial Infarction, Pulse Wave Velocity, SYNTAX II. 


\section{I. ĐĂT VẤN ĐỀ}

NMCT cấp là một trong những nguyên nhân gây tử vong hàng đầu ở Mỹ và các nước châu Âu, ước tính có khoảng một triệu BN nhập viện mối năm khoảng 200.000 đến 300.000 BN tử vong mỗi năm vì NMCT cấp. Bênh để lại nhiều biến chứng nặng nề bao gồm: biến chứng cơ học (thủng vách liên thất, thành tự do của tim, hở van hai lá cấp tính) đến các rối loạn nhịp nguy hiểm và cuối cùng là tử vong [1], [2].

ở Việt Nam bệnh lý do vữa xơ động mạch, trong đó có NMCT cấp có xu hướng gia tăng nhanh chóng. Do đó việc nhận biết các thay đổi mạch máu xơ vữa cận lâm sàng trước khi biểu hiện lâm sàng là rất quan trọng để phân tầng nguy cơ và quản lý tối ưu, cuối cùng là để phòng ngữa bệnh động mạch vành. Xơ cứng động mạch là một trong những biểu hiện sớm của tổn thương mạch máu trước khi có hẹp, tắc các động mạch và gây ra các triệu chứng lẩm sàng. Nhửng thay đổi này có thể được đánh giá gián tiếp qua đo các chỉ số vận tốc sóng mạch (PWV) và huyết áp tâm thu cổ chân-cánh tay (ABI), một công cụ đo đơn giản, không xâm lấn và đáng tin cậy.

Xuất phát từ thực tế trên, chúng tôi tiển hành thực hiện đề tài này nhằm mục tiêu: Tìm hiểu mối liên quan giữa chỉ số $A B I$, PWV với mức độ tổn thương mạch vành thông qua điểm SYNTAX II.

\section{II. ĐỐI TƯỚNG VÀ PHƯƠNG PHÁP NGHIÊN CỨU}

2.1. Đối tượng nghiên cứu. Chúng tôi tiến hành nghiên cứu trên 2 nhóm: Nhóm bệnh gồm $60 \mathrm{BN}$ được chẩn đoán xác định NMCT cấp và nhóm chứng 33 bệnh nhân có cùng độ tuổi, các yếu tố nguy cơ và chụp ĐMV qua da không có tổn thương tại khoa can thiệp tim mạch, Bệnh viện Quân y 103 từ tháng 11/2020 đến tháng 4/2021.

Tiêu chuẩn chẩn đoán NMCT cấp theo định nghĩa toàn cầu lần thứ tư năm 2018 [3].

+ Cách thức tiến hành nghiên cứu:

- Hỏi, khám lâm sàng.

- Làm các xét nghiệm máu để chẩn đoán xác định NMCT cấp.
- Ghi điện tâm đồ, siêu âm tim.

- Tất cá các BN đều được chụp động mạch vành qua da.

- Đo PWV, ABI bằng hệ thống máy Falcon của hãng Viasonix và phần mềm (v.1.6.0, Viasonix, Ltd).

- Đánh giá kết quả bằng phương pháp đo vận tốc lan truyền sóng mạch cổ chân-cánh chẩn (baPWV) thì các nghiên cứu lấy giá trị ngưỡng bình thường là $<14 \mathrm{~m} / \mathrm{s}$.

- Đánh giá tổn thương động mạch vành theo thang điểm SYNTAX II dựa trên hệ thống phần mềm chấm điểm đã được thiết kế sẵn trên trang web SYNTAX Score.

2.2. Phương pháp nghiên cứu. Nghiên cứu mô tả cắt ngang có nhóm so sánh, lây mẫu thuận tiện.

\section{KẾT QUẢ NGHIÊN CỨU}

Bảng 1. Đặc điểm chung nhóm nghiên cứu

\begin{tabular}{|c|c|c|}
\hline \multirow{2}{*}{$\begin{array}{c}\text { Đắc } \\
\text { điểm }\end{array}$} & $\begin{array}{c}\text { Nhóm bếnh } \\
(\mathbf{n = 6 0})\end{array}$ & $\begin{array}{c}\text { Nhóm chứng } \\
(\mathbf{n = 3 3 )}\end{array}$ \\
\cline { 2 - 3 } & Mean $\pm \mathrm{SD} / \mathrm{n}(\%)$ & Mean $\pm \mathrm{SD} / \mathrm{n}(\%)$ \\
\hline Tuối (Năm) & $67,05 \pm 12,04$ & $67,67 \pm 6,80$ \\
\hline Giới (Nam) & $44(73,3)$ & $10(30,3)$ \\
\hline THA & $40(66,7)$ & $26(78,8)$ \\
\hline DTÐ & $13(21,7)$ & $8(24,4)$ \\
\hline RLLP máu & $54(90)$ & $27(81,8)$ \\
\hline Hút thuốc lá & $23(38,3)$ & $4(12,1)$ \\
\hline BMI & $22,66 \pm 2,65$ & $22,84 \pm 3,13$ \\
\hline ABI & $1,04 \pm 0,10$ & $1,12 \pm 0,13$ \\
\hline PWV (m/s) & $15,90 \pm 1,49$ & $13,32 \pm 1,98$ \\
\hline
\end{tabular}

Bảng 2. Đặc điếm tốn thương động mach vành

Đặc điếm tốn thương Mean \pm SD/n(\%)

\begin{tabular}{|c|c|}
\hline Động mạch liên thất trước & $25(41,7)$ \\
\hline Động mạch mũ & $4(6,7)$ \\
\hline Động mạch vành phải & $31(51,7)$ \\
\hline Tô̂n thương 1 nhánh & $20(33,33)$ \\
\hline Tốn thương 2 nhánh & $20(33,33)$ \\
\hline Tốn thương 3 nhánh & $20(33,34)$ \\
\hline Tắc hoàn toàn & $34(56,67)$ \\
\hline Điếm SYNTAX & $17,12 \pm 9,08$ \\
\hline
\end{tabular}

Bảng 3. Mối liên quan giữa ABI và PWV theo số nhánh tổn thương

\begin{tabular}{|c|c|c|c|c|c|}
\hline Số nhánh & $\mathbf{n = 6 0}$ & PWV & P & ABI & P \\
\hline 1 & 20 & $15,25 \pm 1,09$ & $\mathrm{p}<0,05$ & $1,06 \pm 0,12$ & $\mathrm{p}>0,05$ \\
\hline$\geq 2$ & 40 & $16,22 \pm 1,57$ & & $1,03 \pm 0,08$ & \\
\hline
\end{tabular}

\begin{tabular}{|c|c|c|c|c|}
\hline Đăc điểm Chỉ số & \multicolumn{2}{|c|}{ PWV } & \multicolumn{2}{|c|}{ ABI } \\
\hline $\begin{array}{l}\text { Số nhánh ĐMV } \\
\text { tổn thương }\end{array}$ & $\begin{array}{r}r \\
0.502\end{array}$ & $\begin{array}{c}\mathrm{p} \\
<0,001\end{array}$ & $\begin{array}{c}r \\
0.02\end{array}$ & $\frac{p}{>0,05}$ \\
\hline
\end{tabular}

Bảng 5. Môii liên quan giữa ABI, PWV với điểm SYNTAX

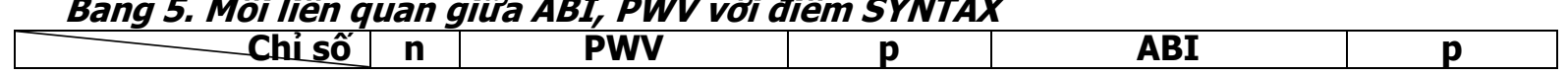


VIETNAM MEDICAL JOURNAL N²0 - DECEMBER - 2021

\begin{tabular}{|c|c|c|c|c|c|}
\hline S.S & 60 & & \multirow{3}{*}{$p<0,05$} & & \multirow{3}{*}{$p>0,05$} \\
\hline$\leq 16$ & 31 & $15,29 \pm 0,99$ & & $1,03 \pm 0,11$ & \\
\hline$>16$ & 29 & $16,55 \pm 1,67$ & & $1,05 \pm 0,09$ & \\
\hline
\end{tabular}

*SS: SYNTAX Score

Bảng 6. Môi tương quan giữa ABI, PWV với điểm SYNTAX

\begin{tabular}{|c|c|c|c|c|}
\hline \multirow{2}{*}{ Đăcc điểm Chỉ số } & \multicolumn{2}{c|}{ Chỉ số PWV } & \multicolumn{2}{c|}{ Chỉ số ABI } \\
\cline { 1 - 5 } Điểm SYNTAX & $\mathrm{r}$ & $\mathrm{p}$ & $\mathrm{r}$ & $\mathrm{p}$ \\
\cline { 2 - 5 } & 0,477 & $<0,05$ & 0,055 & $>0,05$ \\
\hline
\end{tabular}

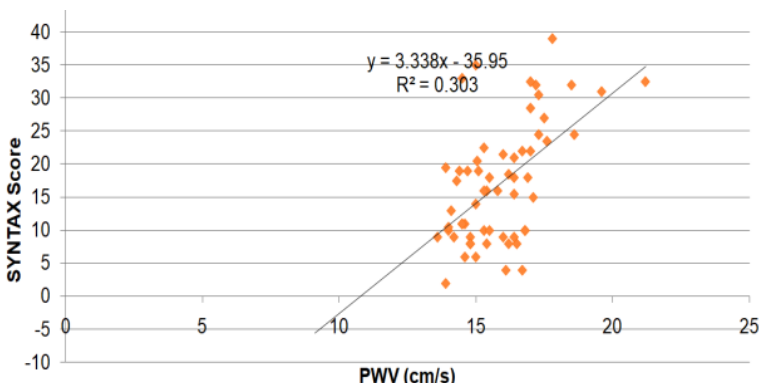

Biểu đồ 1: Phường trình hồi qui tuyến tính giữa PWV với điểm SYNTAX

\section{BÀN LUÂ̂N}

Cứng động mạch là một vấn đề còn khá mới mẻ trong tim mạch học và̀ đang được tập trung nghiên cứu trong nhửng năm gần đây. Về mặt cơ chế, cứng động mạch có liên quan đến nhiều yếu tố như gen di chuyền, vài trò tế bào cơ trơn và nội mạc, sự lão hóa, tăng huyết áp, lượng muối qua khẩu phần ăn, ĐTĐ, suy thận... Nhiều nghiên cứu lâm sàng đã chứng minh cứng động mach gia tăng sẽ làm tăng tỉ lệ tử vong và tỉ lệ mắc bệnh tim mạch. Thay đổi thành mạch có thể được phát hiện sớm cả động mạch nhỏ và lớn thông qua một số phép đo độ cứng động mạch. Trong đó đo vận tốc sóng mạch là tiêu chuẩn vàng giúp xác định động cứng động mạch [4]. Trên lâm sàng có nhiểu phương pháp xác định PWV bằng xâm nhập và không xâm nhập. Phương pháp xâm nhập tuy có độ chính xác cao nhưng thường khó thực hiện và không được áp dụng rộng rãi. Phương pháp không xâm nhập mà chúng tôi thực hiện trong nghiên cứu kết hợp đo chỉ số huyết áp tâm thu cổ chân cánh tay ( $A B I)$ có ưu điểm là thực hiện đơn giản, thời gian ngắn, làm được trên số lượng lớn giúp quá trình sàng lọc và phân tầng nguy cơ dễ dàng hơn. Bên cạnh đó nó có liên quan chặt chẽ với các phương pháp xâm nhập cũng đã được báo cáo trong nhiều nghiên cứu trong và ngoài nước.

Trong nghiên cứu của chúng tôi PWV ở nhóm bệnh nhân có bệnh mach vành cao hơn nhóm chứng cùng độ tuối $(15,90 \pm 1,49$ so với $13,32 \pm 1,98 ; \quad p<0,01)$ và $A B I$ thấp hơn $(1,04 \pm 0,10$ so với $1,12 \pm 0,13 ; p<0,01)$. Kết quả này cũng tương tự nghiên cứu Myslinski $\mathrm{W}$. và CS (2020) nhóm mạch vành có $A B I 0,98 \pm 0,25$, nhóm chứng $1,05 \pm 0,13 ; p<0,01$ [5]. Và nghiên cứu của Koji Y. và CS (2004) nhóm có bệnh mạch vành $A B I \quad 1,04 \pm 0,15$ nhóm chứng $1,11 \pm 0,12 ; \quad \mathrm{p}<0,01$. PWV nhóm CAD

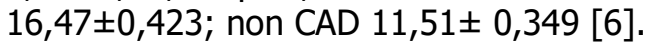

Trong nghiên cứu của chúng tôi các bệnh nhân có bệnh động mạch chi dưới mà $A B I<0,9$ bị loại khỏi nhóm nghiên cứu do ảnh hưởng tới kết quả đo của vận tốc sóng mạch, vì vậy giá trị trung bình của chỉ số $A B I$ của chúng tôi cao hơn với các nghiên cứu trước.

PWV tăng dân cùng với mức độ tổn thương và số nhánh bị tổn thương của động mạch vành. PWV lần lượt là $15,25 \pm 1,09$ ở nhóm tổn thương 1 nhánh so với $16,22 \pm 1,57$ ở nhóm tổn thương 2 nhánh. Trong nghiên cứu của Alarhabi A.Y và $C S$ (2009) công bố cho thấy PWV tăng theo số nhánh động mạch vành tổn thương tăng dần là $11.13 \pm 0.916,15.22 \pm 1.115$ và $19.30 \pm 2.056$ $\mathrm{m} / \mathrm{s}$ ứng với tổn thương 1,2 và nhiều nhánh [7]. Cũng tương tự trong nghiên cứu của Phan Đồng Bảo Linh và CS PWV lần lượt là $9.35 \pm 2.64$, $11.51 \pm 2.01$ và $13.73 \pm 3.24 \mathrm{~m} / \mathrm{s}$ ứng với các nhóm tổn thương 1,2 và 3 nhánh mạch vành chính [8]. Điều này cho thấy mức xơ vữa mạch vành càng nặng lên khi tốc độ sóng mạch gia tăng. Bên cạnh đó PWV cũng có mối tương quan chặt chẽ với mức độ tổn thương mạch vành thồng qua điểm SYNTAX, với $r=0,477 ; p<0,01$. Chang-Min Chung và cộng sự đã nghiên cứu 370 thấy baPWV đều có liên quan đáng kể với điểm SYNTAX $(r=0,525, p<0,001)$ [9]. Zhang Fan và cộng sự nghiên cứu 196 bệnh nhân điểm baPWV và SYNTAX có tương quan thuận có ý nghĩa $(r=$ $0,624, p<0,05)[10]$. Shunyang Sun và cộng sự kết luận baPWV có tương quan thuận với điểm SYNTAX ( $r=0,613, p=0,007)$, trong khi ABI không có mối tương quan với điểm SYNTAX [11].

\section{KẾT LUÂ̂N}

Nhóm BN NMCT cấp có PWV cao hơn và $A B I$ thấp hơn nhóm chứng có ý nghĩa. PWV tương quan chặt chẽ với mức độ tổn thương ĐMV theo thang điểm SYNTAX II ở BN NMCT cấp. 


\section{TÀI LIÊU THAM KHẢO}

1. Wang H., Naghavi M., Allen C., et al. (2016), "Global, regional, and national life expectancy, allcause mortality, and cause-specific mortality for 249 causes of death, 1980-2015: a systematic analysis for the Global Burden of Disease Study 2015", The Lancet, 388(10053), 1459-1544.

2. Benjamin EJ., Blaha MJ., Chiuve SE., et al. (2017), "Heart disease and stroke statistics-2017 update: a report from the American Heart Association", circulation, 135(10), e146-e603.

3. Kristian Thygesen, Joseph S. Alpert, Allan S. Jaffe, et al. (2012), "Third Universal Definition of Myocardial Infarction", Circulation, 126, 2020-2035.

4. Kim HL., Kim SH. (2019), "Pulse wave velocity in atherosclerosis", Frontiers in cardiovascular medicine, 6, 41.

5. Myslinski W., Stanek A., Feldo M., et al. (2020), "Ankle-brachial index as the best predictor of first acute coronary syndrome in patients with treated systemic hypertension", BioMed Research International, 2020.
6. Koji Y., Tomiyama $H_{.,}$Ichihashi $H_{.,}$et al. (2004), "Comparison of ankle-brachial pressure index and pulse wave velocity as markers of the presence of coronary artery disease in subjects with a high risk of atherosclerotic cardiovascular disease", Am J Cardiol, 94(7), 868-72.

7. Alarhabi A.Y., et al. (2009), "Pulse Wave Velocity as a marker of severity of coronary artery disease" J Clin Hypertens (Greenwich): 17-21.

8. Linh Phan Đồng Bảo (2013), Nghiên cứu đăc điểm tổn thương mạch vành và vận tốc sóng mach ở bệnh nhân tăng huyết áp nguyên phát có bệnh mach vành; Đai học y dược Huế, Bộ y tế.

9. Chung CM., Ṫseng Y., Lin YS., et al. (2015), "Association of brachial-ankle pulse wave velocity with atherosclerosis and presence of coronary artery disease in older patients", Clinical interventions in aging, 10, 1369.

10. Zhang F., Liu J., Huang W., et al. (2013), "Associations of SYNTAX score with serum homocysteine and brachial-ankle pulse wave velocity []]", Journal of Chinese Practical Diagnosis and Therapy, 2.

\section{ĐẶC ĐIỂM LÂM SÀNG, CÂ̂N LÂM SÀNG VÀ HIỆU QUẢ ĐIỀU TRI THOÁT VI ĐĨA ĐÊM CộT SỐNG THẮT LƯNG BẰNG TIÊM HYDROCORTISON NGOÀI MÀNG CỨNG}

\section{TÓM TẮT.}

Mục tiêu: Mô tả đăc điểm lâm sàng, cận lâm sàng và đánh giá kết quả điều trị thoát vị đĩa đệm cột sống thắt lưng bằng phương pháp tiêm Hydrocortison ngoài màng cứng. Phương pháp: Nghiên cứu can thiệp trên 80 bênh nhân được chẩn đoán thoát vị đĩa đệm cột sống thắt lưng điều trị tại khoa Thần kinh Bệnh viền Hữu nghi Đa khoa Nghể An năm 2020 - 2021. Kết quả: Tuổi đối tượng nghiên cứu từ $27-86$ tuổi, độ tuổi $30-60$ tuổi chiếm 57,5\%, >60 tuôir chiếm $38,7 \%,<30$ tuổi chiếm 3,8\%. Nữ giới $62,5 \%$, nam giới $37,5 \%$. Nghề nghiệp lao động chân tay chiếm 68,8\%, lao động trí óc 28,8\%. Đặc điểm lâm sàng: Hội chứng cột sống (hạn chế tầm hoạt động CSTL 96,2\%, điểm đau CSTL 91,2\%, giảm chỉ số Schober < $14 / 10 \mathrm{~cm} 88,8 \% \ldots)$ và hội chứng chèn ép rễ thần kinh (dấu hiệu Lasègue (+) 95\%, dấu hiệu 'Chuông bấm' (+) $91,2 \% \ldots)$; về cận lâm sàng: loại thoát vị lồi đĩa đệm 41,2\%, L4 - L5 61,2\%. Sau điêu trị tiêm Hydrocortison ngoài màng cứng, các dấu hiệu giảm rõ rệt. Tỷ lệ điều trị thành công cao chiếm 97,5\%, chuyển phẫu thuật 2,5\%. Kết luận: Nghiên cứu cho thấy tiêm hydrocortisol ngoài màng cứng cải thiện có

${ }^{1}$ Trường Đại học Y khoa Vinh

Chịu trách nhiệm chính: Nguyễn Văn Tuấn

Email: tuanminh1976@gmail.com

Ngày nhận bài: 16.9.2021

Ngày phản biên khoa hoc: 12.11.2021

Ngày duyệt bài: 23.11.2021

\section{Nguyễn Văn Tuấn ${ }^{1}$, Nguyễn Anh Dũng ${ }^{1}$}

ý nghĩa thống kê các triệu chứng lâm sàng ở bệnh nhân thoát vị đĩa đệm cột sống thắt lưng.

Tư khóa: Thoát vị đĩa đệm cột sống thắt lưng, tiêm hydrocortisone ngoài màng cứng.

\section{SUMMARY \\ CLINICAL, PARACLINICAL FEATURES AND EVALUATION OF THE EFFECTIVENESS OF TREATMENT OF LUMBAR DISC HERNIATION WITH EPIDURAL HYDROCORTISONE INJECTION}

Objectives: To describe clinical and paraclinical characteristics; to remark on the outcomes of treatment of lumbar disc herniation with epidural hydrocortisone injection. Methods: Intervention study was conducted on 80 patients who were diagnosed with lumbar disc herniation at the Neurology Department of Nghe An General Hospital in 2020 - 2021. Results: The age of the study subjects was from 27 to 86 , the age from 30 to 60 accounted for $57.5 \%$, over $>60$ accounted for $38.7 \%$, under $<30$ accounted for $3.8 \%$. Female $62.5 \%$, male $37.5 \%$. Occupation of manual labor accounted for $68.8 \%$, mental labor $28.8 \% \ldots$ Clinical features: Spine syndrome (limited range of physical activity $96.2 \%$, pain score $91.2 \%$, decrease in Schober index $<14 / 10$ $\mathrm{cm} 88.8 \% \ldots)$ and nerve root compression syndrome (Lasègue sign (+) 95\%, 'Bell' sign" (+) +) 91.2\%...); on paraclinical: herniated disc type $41.2 \%$, L4 - L5 $61.2 \%$. After treatment with epidural hydrocortisone 